\title{
Waste Heat Recovery Technology Based on Thermoelectric Couple for Fuel Cell
}

\author{
Jia-Ruei $\mathrm{Wu}^{\mathrm{a}}$, Chung-Neng Huang ${ }^{\mathrm{a},{ }^{*}}$ \\ ${ }^{a}$ Graduate Institute of Mechatronic System Engineering, National University of Tainan, 33, Sec. 2, Shu-Lin St., Tainan 700, \\ Taiwan
}

*Corresponding Author: kosono@mail.nutn.edu.tw

\begin{abstract}
In recent years, due to global warming and carbon emissions increase, many countries focus on the development of green energy, and waste heat recovery technology is also noticed. Hydrogen is a new energy that is clean, efficient and sustainability, wherein fuel cells attract attention that can transform energy from hydrogen to electricity directly without exhausting gas but heat. In this paper, thermoelectric couple is used to recover the waste heat from fuel cell into electricity power to provide vehicle required or other devices. The simulation result shows that thermoelectric couple can efficiently deal with above work. In addition, an intelligent controller will be designed to improve the output stability of renewable system.
\end{abstract}

Keywords: Thermoelectric Couple, Proton Exchange Membrane Fuel Cell, Waste Heat Recovery.

\section{Introduction}

In recent years, due to the petrochemical energy shortage, global warming, and the Carbon emissions increase, many countries focus on the development of green energy, and the system efficiency and recoverability are also noticed. Hydrogen is a new energy that is clean, efficient and sustainability, so it soon gets the international attention.

Fuel cells are the most promising energy technology, the principle is the reverse reaction of electrolyzed water, injects hydrogen and oxygen into the anode and cathode plate, and it generates power, water and heat. Its applications include transportation and power plants.

The Seebeck Effect was first discovered in metal in 1821. It's foundation of thermoelectric effect ${ }^{(1)}$. When a thermoelectric couple has temperature difference across two side, it will generate voltage. When input voltage to it, it will generate temperature difference.

In the past studies, they recover waste heat based on thermoelectric couples (TEC) for proton exchange membranes fuel cells (PEMFC), but the number of the TEC was less, so the voltage generated was lower. It cannot be used effectively in other device. Therefore, we think that we can increase the number of TEC to generate more voltage. It can be used to the battery charging or the motor operation.

In this study, we use MATLAB/SIMULINK to build a model of PEMFC and TEC to simulate the waste heat recovery of fuel cell, and use thermoelectric couple to transform the waste heat to electric power.

\section{Matlab Mathmatical Model}

\subsection{Worldwide Harmonized Light Vehicles Test Procedure}

We use Worldwide Harmonized Light Vehicles Test Procedure (WLTP) to simulate the real road conditions, WLTP is a globally unified driving cycle measurement standard, it sets some driving conditions to measure the speed of the vehicle as shown in Fig. 1.

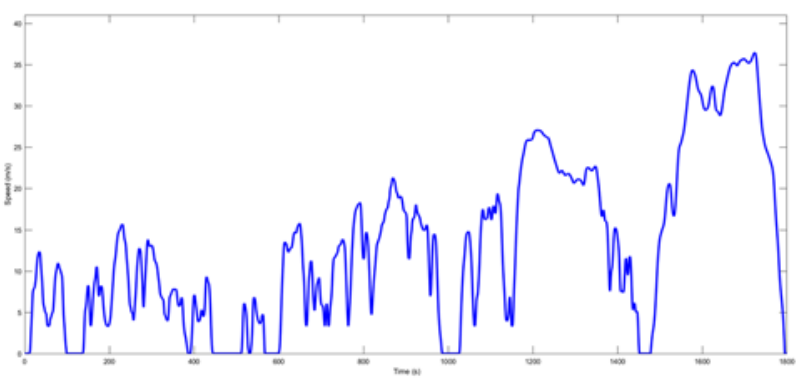

Fig. 1. WLTP 
However, the unit of WLTP is speed, so I have to transform the unit to power (W), the unit transform can use the Eq. 1 . In this equation, $P$ is the power required of the vehicle, $M$ is the mass of the vehicle, $g$ is gravitational acceleration $9.81 \mathrm{~m} / \mathrm{s}^{2}, f_{r}$ is the rolling resistance coefficient of the tire, $\rho_{a}$ is air density $1.202 \mathrm{kfg} / \mathrm{m}^{3}, C_{D}$ is air resistance coefficient of the vehicle, $A_{f}$ is the front half area of the vehicle, $V$ is speed of the vehicle and the unit is $m / s$.

$$
\begin{gathered}
P_{v}=\left(M \times g \times f_{r}+\frac{1}{2} \rho_{a} C_{D} A_{f} V^{2}\right. \\
\left.+M \frac{d V}{d t}\right) \times V
\end{gathered}
$$

\subsection{PEM Fuel Cell Model}

(A) Electrical model

When a cell provides power to the load, the no-load voltage $\left(V_{n}\right)$, is reduced by three classes of voltage drop, the activation $\left(V_{\text {act }}\right)$, ohmic $\left(V_{\text {ohm }}\right)$, and concentration $\left(V_{\text {conc }}\right)$.

There is a polarization curve which is generally used to express the feature of a FC as shown in Fig. 2.

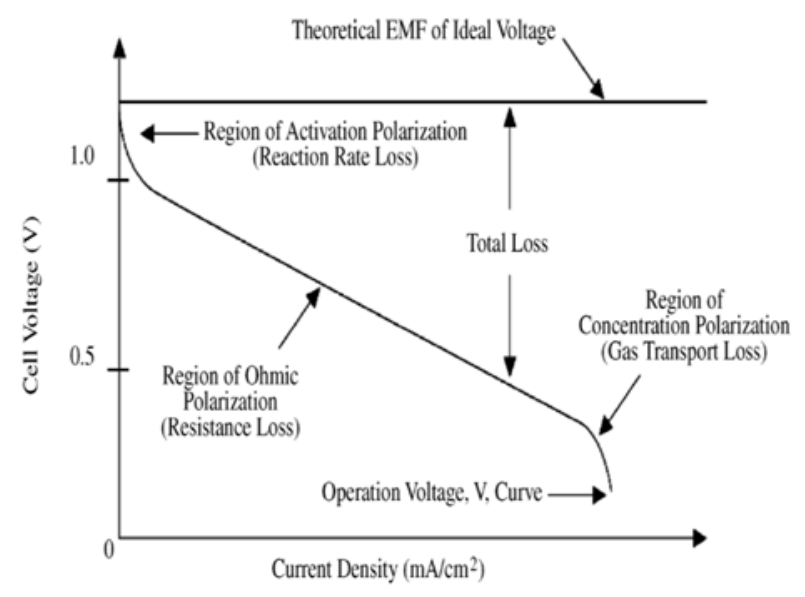

Fig. 2. Polarization curve.

In general, the voltage of the $\mathrm{FC}$ could be found using Eq. 1.

$$
V_{\text {cell }}=V_{n}-V_{\text {act }}-V_{\text {ohm }}-V_{\text {conc }}
$$

(a) Nernst voltage

The Nernst equation can calculate the total voltage of the cell, the equation is as Eq. 2. The $V_{0}$ ideal voltage is $1.229 \mathrm{~V}$

$$
V_{n}=V_{0}+\frac{R T}{2 F} \ln \left(P_{H_{2}} \times\left(P_{O_{2}}\right)^{\frac{1}{2}}\right)
$$

$R$ is universal gas constant, T is stack temperature the unit is ${ }^{\circ} \mathrm{K}, \mathrm{F}$ is Faraday constant, $P_{\mathrm{H}_{2}}$ is pressure of hydrogen, $P_{\mathrm{O}_{2}}$ is pressure of oxygen. (b) Activation polarization

Activation polarization can be analyzed by Tafel's equation, if the current density is larger, the electrode potential is more deviated from the equilibrium, so the required voltage is larger ${ }^{(2)}$.

$$
V_{a c t}=\frac{R T}{\alpha n F} \ln \frac{i}{i_{0}}
$$

$\alpha$ is the constant between $0-1$ that is the electron transfer coefficient of hydrogen and oxygen in the reaction, $n$ is the number of electrons released during the reaction, $i$ is the cell current density, $i_{0}$ is the current density released during the hydrogen ion and oxygen ion reaction.

(c) Ohmic polarization

Ohmic polarization is the consumption effect when ions, charged defects, electron holes or electrons are transported within the electrolyte or the electrode.

$$
V_{\text {ohm }}=A I R_{r}
$$

$A$ is reaction area, $I$ is current density, $R_{r}$ is the total resistance of the cell.

(d) Concentration polarization

At high current densities, reactants transport to the reaction sites slowly is the main reason for the concentration polarization $^{(3)}$.

$$
V_{\text {con }}=\frac{R T}{n F} \ln \left(1-\frac{i}{i_{L}}\right)
$$

$i_{L}$ is the limiting current density.

(B) Thermal model

In a FC, only a little of the internal energy in the hydrogen can be converted into electricity, the remaining energy is either dissipated or absorbed by the FC, it causes the FC operating temperature increase ${ }^{(4)}$. Based on the thermal energy balance applied to the $\mathrm{FC}$, the equation is:

$$
Q_{n}=Q_{g}-Q_{e}
$$

$Q_{n}$ is system's internal heating power acquired, $Q_{g}$ is heating power generated, $Q_{e}$ is heating power dissipated.

The FC heat generation is due to the heating power released by the chemical reaction $\left(Q_{c}\right)$, the electrical power generated by the $\mathrm{FC}\left(P_{S}\right)$ and the heating power associated with the sensible and latent heat $\left(Q_{s e+l a}\right)$ of the reactants and the reaction product ${ }^{(4)}$. $Q_{g}$ is represented by the following equation:

$$
Q_{g}=Q_{c}-P_{s}-Q_{s e+l a}
$$

$Q_{c}$ is the quantity of energy entering the system per time unit. It depends on the enthalpy potential of the FC and the electron transfer rate in the reaction ${ }^{(4)}$. So, the equation is: 


$$
Q_{c}=\frac{\Delta h_{f, H_{2} O, 1}^{0}}{z F} N_{s} i_{s}
$$

$\Delta h_{f, H_{2} O, 1}^{0}$ is the enthalpy of liquid water formation (285.84 $\mathrm{kJ}$ mol-1 at $25^{\circ} \mathrm{C}$ and $1 \mathrm{bar}$ ), $N_{s}$ is number of series cells, $i_{S}$ is current of the FC.

$P_{S}$ is power of the $\mathrm{FC}$, it obtained through voltage $\left(V_{F C}\right)$ and the $\mathrm{FC}$ stack current, the equation is:

$$
P_{s}=V_{F C} i_{s}
$$

$Q_{s e}$ is sensible heat that is defined as heat received by a substance and which cause the temperature increased without affecting its state ${ }^{(4)}$.

$Q_{l a}$ is latent heat that is defined as the energy required for a substance to change phase ${ }^{(4)}$.

$$
\begin{aligned}
Q_{s e+l a}= & m_{H_{2}} c_{p, H_{2}}\left(T-T_{a}\right)+ \\
& m_{O_{2}} c_{p, O_{2}}\left(T-T_{a}\right)+ \\
& m_{H_{2} O} H_{v, H_{2} O}
\end{aligned}
$$

$m_{\mathrm{H}_{2}}$ is the mass flow rate of hydrogen, $m_{\mathrm{O}_{2}}$ is the mass flow rate of oxygen, $m_{\mathrm{H}_{2} \mathrm{O}}$ is the mass flow rate of water, $c_{p}$ is specific heat, $H_{v}$ is enthalpy of vaporization, $T$ is FC operating temperature, $T_{a}$ is ambient temperature.

$Q_{e}$ is heating power dissipated that is defined as the product between the heat transfer coefficient $\left(H_{t}\right)$ and the temperature difference between $T$ and $T_{a}{ }^{(4)}$. The equation is:

$$
Q_{e}=H_{t}\left(T-T_{a}\right)
$$

\subsection{Thermoelectric Couple Model}

Thermoelectric couple is a device that can generate electric power by using temperature difference ${ }^{(1)}$, it is based on Seebeck Effect. The Seebeck Effect was first discovered in metal in $1821^{(1)}$, Thomas Johann Seebeck found when the two different metals compose a closed loop and the temperature on the junction is different, the compass pointer is deflected. Therefore, he thought the temperature difference caused the metal to produce a magnetic field, but he did not discover the current in the closed loop, so he called the phenomenon "thermomagnetic effect". Danish physicist Hans Christian Ørsted rectified the oversight and coined the term "Thermoelectric Effect". Thermoelectric couple (TEC) is a kind of semiconductor material ${ }^{(5)}$, composed by many thermoelectric wafers as shown in Fig. 3.

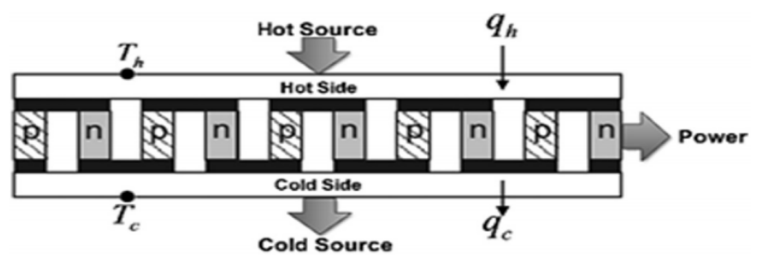

Fig. 3. A typical configuration of $\mathrm{TEC}^{(6)}$.
In Fig. 3, hot side temperature of module is $T_{h}$, cold side temperature of module is $T_{c}$, and we can calculate the temperature difference $\left(D_{t}\right)$ by Eq. 12 .

$$
D_{t}=T_{h}-T_{c}
$$

$q_{h}$ is output heat from module, it can be obtained as

$$
q_{h}=\left(S_{M} I T_{h}\right)+K_{M} D_{t}-\frac{I^{2} R_{M}}{2}
$$

$q_{c}$ is input heat to module, it can be obtained as

$$
q_{c}=\left(S_{M} I T_{c}\right)+K_{M} D_{t}+\frac{I^{2} R_{M}}{2}
$$

In Eq. 13 and 14, $S_{M}$ is Seebeck coefficients, I is output current from module, $K_{M}$ is the thermal conductance of module, $R_{M}$ is resistance of module.

The voltage generated by the Seebeck Effect can be obtained as

$$
V_{\text {out }}=D_{t} \times S_{M}
$$

In Eq. 13-15, Seebeck coefficients and thermal conductance are different in every metal materials, so the parameters of Seebeck coefficients and thermal conductance must be changed in different metal materials.

\subsection{Cooling Plate}

PEMFC have high power density while operating at relatively low temperatures (about $\left.80^{\circ} \mathrm{C}\right)^{(7)}$. Therefor, heat dissipation of PEMFC is very important, if the temperature is too high, polymer membrane inside will burn ${ }^{(7)}$.

This is traditional cooling plate as shown in Fig. 4.

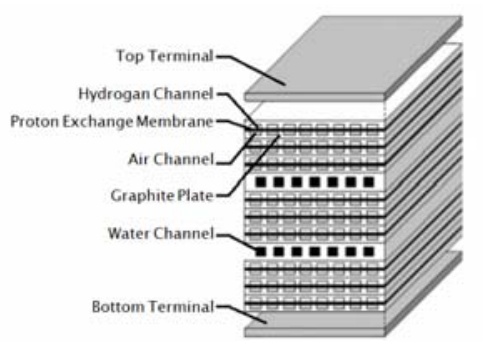

Fig. 4. Traditional cooling plate ${ }^{(7)}$.

In the simulation, we embed the TEC in the cooling plate as shown in Fig. 5, and the TEC absorb heat of PEMFC and then dissipate heat through the cooling plate.

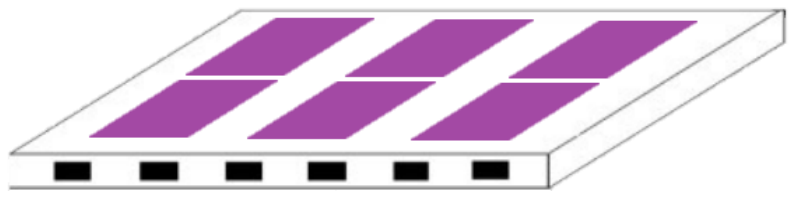

Fig. 5. TEC embed in cooling plate.

The temperature of solid region of the cooling plate is $T_{S}$, and we can calculate $T_{S}$ by Eq. 16.

$$
T_{s}=\frac{q}{h}+T_{w}
$$


$q$ is heat flux, $h$ is heat transfer coefficient, $T_{w}$ is water temperature $^{(7)}$.

\section{Result}

In the simulation, we use Eq. 1 to calculate the power required of the vehicle in drivecycle of WLTP. The result is two cycles show in Fig. 6. This is the input of PEMFC.

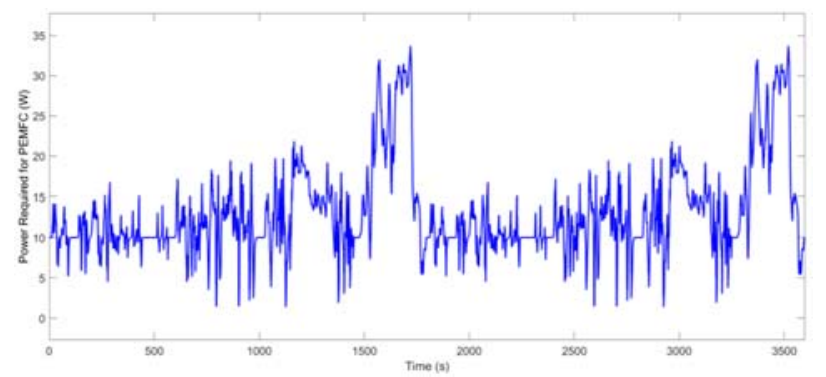

Fig. 6. Power for PEMFC.

After calculating the power required, put it into PEMFC model, and then we can get the operation temperature of PEMFC shown in Fig. 7.

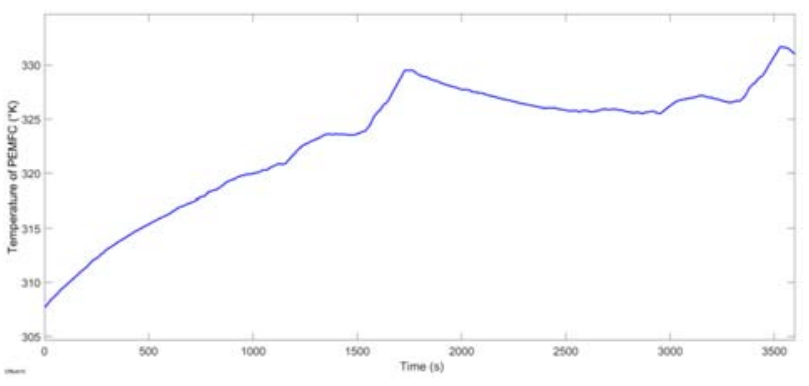

Fig. 7. Temperature of PEMFC.

This value is the most important of all. After calculating the temperature, we put it into TEC model to generate the voltage. Assume that the water temperature is constant at 25 ${ }^{\circ} \mathrm{C}, D_{t}$ can be calculated by Eq. 12 shown in Fig. 8 .

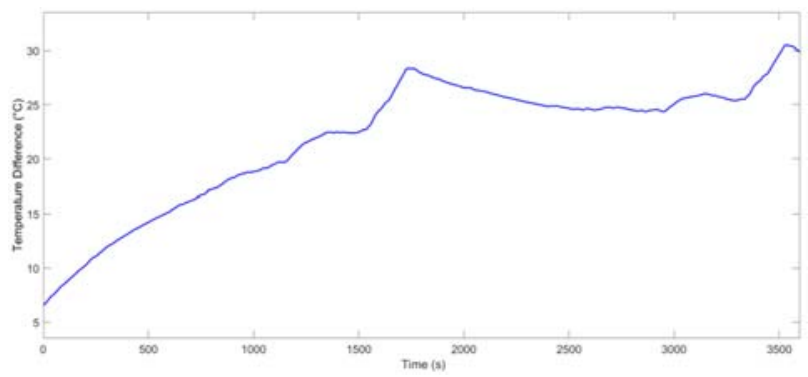

Fig. 8. Temperature difference $\left(D_{t}\right)$.
The voltage of each TEC can be calculated by Eq. 15 shown in Fig. 9.

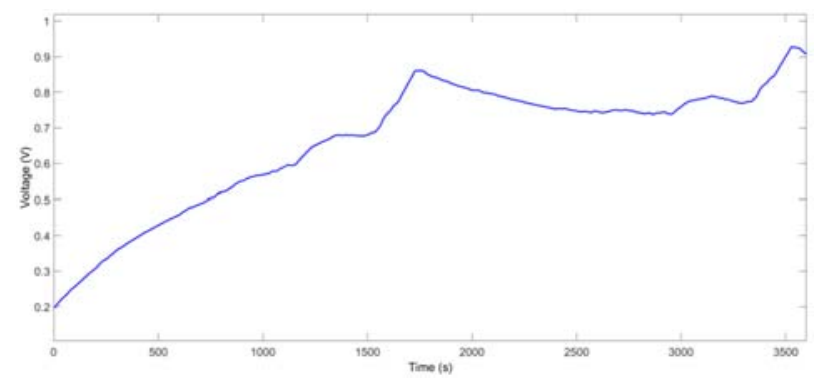

Fig. 9. Voltage of TEC.

\section{Discussion}

The optimum operating temperature of PEMFC is about $333 \mathrm{~K}$ to $335 \mathrm{~K}$. The simulation results of Fig. 9 indicate that, about $0.9 \mathrm{~V}$ of voltage can be generated in about $333 \mathrm{~K}$. Therefore, assume that there 65 PEMFC stacks are used and stuck with 64 TECs to recycle the waste heat energy, and connect TECs in series, the total voltage is about $58 \mathrm{~V}$. However, the more number of TECs increased, the higher voltage can be generated. The power generated by TECs can be used to charge the battery, if PEMFC cannot provide power to the motor suddenly, TECs can provide power urgently until PEMFC is operating normally.

\section{Conclusions}

After the simulation, we verify that the temperature is larger, the voltage generated by TEC is larger. In the result, when the PEMFC operating temperature is about $333 \mathrm{~K}$ to $335 \mathrm{~K}$, and the total voltage generated by TECs is about 58 $\mathrm{V}$, the more number of TECs increased, the higher voltage can be generated. However, Seebeck coefficients and thermal conductance are different in every metal materials, so select the most suitable materials to achieve the best efficiency is very important. The operation temperature of PEMFC is about $80{ }^{\circ} \mathrm{C}$ to $100{ }^{\circ} \mathrm{C}$, there is no waste heat recovery system can recover the waste heat in this range in general. So it is the most outstanding characteristic of TEC. In future work, we will find the number of TECs and the best configuration in series or in parallel. There is an intelligent controller will be designed to improve the output stability of renewable system. 


\section{References}

(1) Y. Wu, L. Zuo, J. Chen, and J. A. Klein : "A model to analyze the device level performance of thermoelectric generator", Journal of Energy, Vol. 115, pp. 591-603, 2016

(2) H. M. Poggi-varaldo and O. Solorza-feria : "Tafel equation based model for the performance of a microbial fuel cell", Journal of Hydrogen Energy, Vol. 94, No. 55, pp. 17421-17432, 2015

(3) C. Wang, S. Member, M. H. Nehrir, S. Member, and S. R. Shaw : "Dynamic Models and Model Validation for PEM Fuel Cells Using Electrical Circuits", IEEE Transactions, Vol. 20, No. 2, pp. 442-451, 2005

(4) I. S. Martín, A. Ursúa, and P. Sanchis : "Modelling of PEM fuel cell performance: Steady-state and dynamic experimental validation", Journal of Energies, Vol. 7, No. 2, pp. 670-700, 2014

(5) J. H. Jiang and Y. Imry : "Linear and Nonlinear Mesoscopic Thermoelectric Transport with Coupling to Heat Baths", Journal of arXiv, Vol. 1, No. 3, pp. 1-11, 2016

(6) M. Hasani and N. Rahbar : "Application of thermoelectric cooler as a power generator in waste heat recovery from a PEM fuel cell - An experimental study", Journal of Hydrogen Energy, Vol. 40, No. 43, pp. 1504015051, 2015

(7) F. C. Chen, Z. Gao, R. O. Loutfy, and M. Hecht : "Analysis of Optimal Heat Transfer in a PEM Fuel Cell Cooling Plate", Journal of Fuel Cells, Vol. 3, No. 4, pp. 181-188, 2003 